\title{
Models of bus boarding and alighting dynamics
}

\section{Journal Article}

Author(s):

Sun, Lijun; Tirachini, Alejandro; Axhausen, Kay W. (D); Erath, Alexander; Lee, Der-Horng

Publication date:

2014-11

Permanent link:

https://doi.org/10.3929/ethz-b-000068608

Rights / license:

In Copyright - Non-Commercial Use Permitted

Originally published in:

Transportation Research Part A: Policy and Practice 69, https://doi.org/10.1016/j.tra.2014.09.007 


\title{
Models of Bus Boarding and Alighting Dynamics
}

\author{
Lijun Sun ${ }^{1,2}$, Alejandro Tirachini ${ }^{3}$, Kay W. Axhausen ${ }^{1,4, *}$, Alex Erath ${ }^{1}$, Der-Horng Lee ${ }^{2}$ \\ ${ }^{1}$ Future Cities Laboratory, Singapore-ETH Centre, Singapore, 138602, Singapore \\ ${ }^{2}$ Department of Civil \& Environmental Engineering, National University of Singapore, Singapore, \\ 117576, Singapore \\ ${ }^{3}$ Transport Engineering Division, Civil Engineering Department, Universidad de Chile \\ ${ }^{4}$ Institute for Transport Planning and Systems (IVT), Swiss Federal Institute of Technology, Zurich, \\ 8903, Switzerland
}

\section{*Corresponding author. Email: axhausen@ivt.baug.ethz.ch (Kay W. Axhausen)}

Understanding the dynamics of boarding/alighting activities and its impact on bus dwell times is crucial to improving bus service levels. However, research is limited as conventional data collection methods are both time and labour intensive. In this paper, we present the first use of smart card data to study passenger boarding/alighting behaviour and its impact on bus dwell time. Given the nature of these data, we focus on passenger activity time and do not account for the time necessary to open and close doors. We study single decker, double decker and articulated buses and identify the specific effects of floor/entrance type, number of activities and occupancy on both boarding and alighting dynamics. A linear relationship between average boarding and alighting times and their respective standard deviations is also found, whereas the variability of boarding and alighting time decreases with the number of passengers boarding and alighting. After observing the cumulative boarding/alighting processes under different occupancy conditions, we propose a new model to estimate passenger activity time, by introducing critical occupancy - a parameter incorporating the friction between boarding/alighting and on-board passengers. We conduct regression analyses with the proposed and another popular model for simultaneous boarding/alighting processes, finding that the critical occupancy plays a significant role in determining the regime of boarding and alighting processes and the overall activity time. Our results provide potential implications for practice and policy, such as identifying optimal vehicle for a particular route and modelling transit service reliability. 


\section{Introduction}

The operating time of bus services comprises driving time between stops and dwell time at stops. Generally, driving time between successive stops depends on the speed profile of the bus, the length of the link, driver behaviour, availability of bus lanes, schedules and timetables, availability of active control strategies, and further factors such as signal control (Abkowitz and Engelstein, 1983). Dwell time is the time in which a public transport vehicle is stopped to transfer passengers, including the time necessary to open and close doors, plus any other time in which a bus has the doors open without passenger service. Dwell time starts with the opening and ends with the closing of bus doors, allowing passengers to board and alight. Dwell time may cover a great proportion of total travel time, which shows the significance of boarding and alighting processes on bus operation. For example, Levinson (1983) found, for US operations observed from 1957-1980 in many cities, that dwell time made up about $20 \%$ of total travel time within urban areas and increased to $26 \%$ in the CBD on average, and recently Tirachini (2013) found in Sydney that dwell time is around $15 \%$ of total travel time with on-board fare payments.

An important issue that has received little attention in the literature is the estimation and analysis of the variability of bus dwell time, which has implications on bus operation and on the satisfaction of bus users, for whom it is valuable to have reliable public transport systems and predictable travel times. However, given the random nature of passenger turnover, dwell time is difficult to control even when the bus driver is experienced. Together with congestion and demand heterogeneity, the variation of dwell time is one of the major factors in the unreliability of bus operations, resulting in bus bunching and over-crowdedness (Newell et al., 1964; Strathman and Hopper, 1993). The dynamics of the boarding and alighting process also depend on various vehicle characteristics, such as the number and width of doors, the existence of steps to board and alight, the type of bus (single/double decker, rigid/articulated), the number of seats and space for standees, and the fare collection method (Guenthner and Hamat, 1988; York, 1993; TRB, 2000; Dorbritz et al., 2009; Fernández et al., 2010; Tirachini, 2013, Fletcher and El-Geneidy, 2013). Therefore, to model and estimate dwell time accurately at bus stops becomes one of the main challenges involved in predicting bus travel time.

A high variability of bus dwell times is likely to produce unreliable travel times, with negative effects for both bus operators and users, because operators have to adjust the length of recovery times at terminals (Furth, 2000). Public transport users prefer reliable travel times (Bates et al., 2001; Hollander, 2006; Batley and Ibáñez, 2009), to the point that travel time variability influences users 
decisions on mode and route choice. Importantly, the social cost of unreliability in public transport might be significant, for instance, van Oort (2011) estimates a yearly cost of $€ 12$ million in The Hague, Netherlands, due to unreliable buses and trams. Therefore, a better understanding of travel time variability in all its components, including dwell time can be used in the operational and tactical planning of public transport operations and scheduling, and for the estimation of the economic and social benefits and costs of alternative systems of public transport service provision, benefiting both bus operators and users (Tirachini et al., 2013).

In this paper, we analyse passenger boarding and alighting dynamics at a microscopic user-byuser level by using individual transactions generated from the smart card-based automated fare collection (AFC) system of Singapore, in which passengers are required to tap on at the front door and suggested to tap off at the rear door(s) (Lee et al., 2012). As summarized in (Pelletier et al., 2011), such data set provides new insights in reconstructing public transport operations at diverse scales, from strategic to tactical to operational management. To date, most studies utilizing smart card data focus on macroscopic characteristics such as adjusting services, designing networks, understanding demand variation and user habits, and measuring service performance, while the microscopic level is generally neglected. By constructing detailed bus operation logs we present detailed models of passenger boarding and alighting behaviour under different occupancy levels and bus characteristics, and study their impact on bus dwell time. Note that such an operation log contains only passenger tapping-in/out activities, imposing an inherent limitation on our study: the time to open and close doors, which is also part of the dwell time, is unknown to us. Given the limitation of using smart card data as a proxy, we study the total passenger activity time between the first and the last tapping-in/out activities as a proxy which is called passenger activity time throughout this paper. ${ }^{1}$ The contributions of this paper are twofold: First, we characterise the boarding/alighting dynamics (behaviour) of users under different bus characteristics in a microscopic framework, allowing us to identify processes that have not been observed in previous dwell time studies. Second, we provide insights on the characterisation of the variability of passenger activity time, an issue that can be analysed in-depth with our smart card data. Implications for policy on bus service operation and planning follow in the conclusions.

The remainder of this paper is organized as follows: in the next section, we review existing studies on bus dwell time; in Section 3 the data employed in this study is described; in Section 4, we

\footnotetext{
${ }^{1}$ Note that our analysis does not capture passenger activity time fully because if we have $N$ passengers boarding or alighting, only $N-1$ intervals are observed: the time for the first boarding passenger and for the last alighting passenger are not computed.
} 
reconstruct the boarding/alighting processes and identify the boarding/alighting interval patterns for different types of buses. After observing the time-stamped boarding/alighting processes, in Section 5 we propose a new passenger activity time model for bus services on which passengers are required to board at the front door and suggested to alight at the rear door; the performance of the proposed model is analysed in Section 6; and finally Section 7 summarizes the main findings of the study and provides the outlook for future work.

\section{Background}

In exploring the determinants of bus dwell time, a number of studies have been conducted since 1970s, e.g. Kraft and Bergen, 1974; Levinson, 1983; York, 1993; Weidmann, 1994; Lehnhoff and Janssen, 2003; Dueker et al., 2004; Fernández et al., 2010; Currie et al., 2013). The common approach is the use of simple or multivariate regressions to relate dwell time to the number of passengers boarding and alighting, the number of passengers inside the vehicle, the number of doors and other variables. Most studies define dwell time as the time for boarding and alighting of passengers plus the time to open and close doors. Levinson (1983) modelled bus dwell time Dw as the sum of the passenger activity time (depends on total number of boarding and alighting passengers) and the time for door opening and closing:

$$
D w=t \times N+t_{d}
$$

where $t$ is the average boarding or alighting time per passenger, $N$ is the number of passengers including both boarding and alighting passengers, and $t_{d}$ is the time spent on opening and closing the doors. In general, if $D w$ is the total time in which doors are open at bus stops, time $t_{d}$ is longer than the time required for the physical opening and closing of doors, as it can include a safety margin used by drivers between the last boarding or alighting and the moment they activate the process to close doors, any dead time in between boardings and alightings at one or several doors, and possibly recovery time introduced in specific stops to adjust to a schedule. Guenthner and Sinha (1983) also assumed that dwell time is governed by the sum of boarding and alighting passengers, and proposed a nonlinear model that contains two sub-functions for the number of passengers. Later, Lin and Wilson (1992) developed linear and nonlinear dwell time models for light rail transit services using the number of passengers and standees as independent variables. Li et al. (2006) developed a binary choice model to study passengers' preference for the front or rear door when alighting and applied the model to estimate dwell time. Other researchers have analysed the influence on boarding and 
alighting times of several vehicle characteristics and passenger related factors, including bus door width (Fernández et al., 2010), and bus floor height (Dueker et al., 2004; Fernández et al., 2010), articulated vehicle body (El-Geneidy and Vijayakumar, 2011; Moreno González et al., 2012), lift operation (Dueker et al., 2004), alternative fare payment techniques (Guenthner and Hamat, 1988; Dorbritz et al., 2009; Fletcher and El-Geneidy, 2013; Tirachini, 2013), age of passengers (Tirachini, 2013) and crowding or friction effects among passengers boarding, alighting and on-board (Lin and Wilson, 1992; Dueker et al., 2004; Milkovits, 2008; Tirachini, 2013; Currie et al., 2013). For example, after analysing streetcar dwell time in Melbourne, Currie et al. (2013) found that crowding effects were more important than the presence of entrance steps in their influence on dwell time.

Taken together, the main stream of dwell time studies distinguish between sequential and simultaneous boarding and alighting. In a sequential model, all bus doors are sequentially used for both boarding and alighting, then dwell time is modelled as:

$$
\text { Model I } D w=a \times A+b \times B+t_{d} \text {, }
$$

where $A$ and $B$ are number of boarding and alighting passengers, respectively. Correspondingly, $a$ and $b$ represent the marginal time (interval) for boarding and alighting per passenger. For simultaneous boarding and alighting when one bus door is used for boarding (usually the front door) and the remaining doors are used for alighting, dwell time is then estimated as the maximum of boarding time and alighting time:

$$
\text { Model II Dw }=\max \{a \times A, b \times B\}+t_{d},
$$

where the notations are the same as Equ. (2). These models have been applied in transit assignment models (Aashtiani and Iravani, 2002; Larrain and Muñoz, 2008) and agent-based simulations (Meignan et al., 2007).

Once a functional form for the dwell time is proposed, the primary task is to estimate its parameters; and therefore, comprehensive data collection is necessary. However, as commonly used techniques are on-board ride checking and on-stop observation, such data collection is known to be both time consuming and labour intensive. For example, the data collection in (Moreno González et al., 2012) required at least two well-trained on-board observers for an articulated bus. As a result, most dwell time studies are limited by their sample sizes.

On the other hand, the behaviour patterns of passengers are a key to understand the dynamics of crowds, in particular at transportation terminals and on transit vehicles (Weidmann, 1992; Helbing et 
al., 2005). However, the physical counting techniques fail to capture the dynamics of passenger behaviour. To replace the physical surveying, video recording devices are employed firstly in microphysical experiments, from understanding pedestrian walking behaviours (Daamen and Hoogendoorn, 2003; Helbing et al., 2005), to exploring vehicle boarding/alighting dynamics (Daamen et al., 2008; Rudloff et al., 2011). Laboratory experiments have also been used to estimate bus dwell times, to analyse elements that are difficult to study in actual bus systems (Fernández et al., 2010). However, given the considerable human resources and device costs, these experiments are usually expensive to conduct: their application in non-laboratory contexts is limited as well.

Recently, with the development of automated vehicle location (AVL) and automated passenger counting (APC) system, Rajbhandari et al. (2003) and Dueker et al. (2004) implement studies on dwell time with the large datasets extracted from AVL and APC, which are used to estimate average boarding and alighting times with regression models. Still, to date, there is no detailed analysis of boarding and alighting behaviour at a microscopic passenger-to-passenger level, for which a system based on smart card transactions, is well suited as the exact time in which a person taps in and off is recorded, therefore passenger intervals are instantly recorded. Therefore, new opportunities to study boarding/alighting dynamics and dwell time at a microscopic level arise from the presence of smart card based automated fare collection systems.

\section{Data Collection}

Two data sources are used here to explore the nature of bus dwell times. First, to uncover the patterns of boarding and alighting behaviour, in particular, any friction effects from on-board passengers, the smart card transactions mentioned above are used. The second database contains the detailed descriptions of buses and is used to analyse the impact of different bus characteristics, such as the number of doors and the vehicle size.

\subsection{Smart Card Data}

The first dataset is smart card data from the public transport system in Singapore, containing bus trip transaction records over one full week, from 11 April 2011 (Monday) to 17 April 2011 (Sunday). The data was collected from more than 3.3 million anonymized smart card users across the whole city state.

The smart card system was introduced in Singapore in April 2002, as part of the citywide Automated Fare Collection (AFC) systems. One of the main purposes of this system is to decrease cash transactions, lowering the cost of handling cash and minimizing the traditionally 
disproportionate impact on ticket cost. After introducing the system, transit agencies and users enjoyed a successful switch from cash to smart card payment. Although cash payment is still available, payments made by smart card systems can enjoy fare discount for a single trip from $4 \%$ to $10 \%$ and additional transfer rebates, covering 97\% of total transit trips in Singapore in the year 2008 (Prakasam, 2008). The use of smart card system has greatly improved the overall speed and efficiency of public transit systems. Commuters do not have to check fares in advance, as they can just present their card and the system will calculate fares using service number, direction, and boarding/alighting stops to deduct payment from each smart card. Different from other smart card systems with no information about alighting (Barry et al., 2002; Munizaga and Palma, 2012), the system in Singapore records not only boarding but also alighting activities. When a user is tapping on or off from a bus, the timing, stop ID and user ID are recorded. Apart from the spatial-temporal records, the registration number of each vehicle and the passenger type (children, adult, senior citizens) are stored. Thus, given its rich content, the smart card data enables us to reconstruct the operation log of each bus.

In this study, we select the records from 8 bus services over the full week, covering different operating companies and various bus models, the detailed characteristics of which are introduced next derived from a separate data source.

\subsection{Bus Characteristics}

The second dataset, which is a lookup dictionary with the registration number as its key, provides a detailed description of each bus. The content includes, but is not limited to, manufacturer, model, length, year of use, entrance type, exact capacity including both seating and standing passengers, engine model, and emission standard. This dataset is available at SgWiki². There are eight different bus types in our database, as listed in Table 1. Bus types are noted with their names and corresponding floor type and entrance types.

\footnotetext{
${ }^{2}$ http://sgwiki.com/wiki/Buses, accessed 18/03/2013.
} 
Table 1, Bus type classification and detailed characteristics

\begin{tabular}{|c|c|c|c|c|c|c|}
\hline Notation & Name & $\begin{array}{c}\text { Floor } \\
\text { D }\end{array}$ & $\begin{array}{c}\text { Entran } \\
\text { ce } \\
\text { S }\end{array}$ & $\begin{array}{c}\text { Capa } \\
\text { city } \\
\text { Cap }\end{array}$ & $\begin{array}{c}\text { Length } \\
{[\mathrm{m}]}\end{array}$ & $\begin{array}{c}\text { Alight } \\
\text { ing } \\
\text { doors }\end{array}$ \\
\hline LL double decker, step & $\begin{array}{c}\text { Leyland } \\
\text { Olympian 3-Axle }\end{array}$ & Double & Step & 131 & 12 & 1 \\
\hline $\begin{array}{c}\text { VL B9 double decker, low } \\
\text { floor }\end{array}$ & Volvo B9TL & Double & $\begin{array}{c}\text { Low } \\
\text { floor }\end{array}$ & 131 & 12 & 1 \\
\hline $\begin{array}{c}\text { SC K230 VI single decker, } \\
\text { low floor }\end{array}$ & $\begin{array}{c}\text { Scania K230 UB } \\
\text { Euro VI }\end{array}$ & Single & $\begin{array}{c}\text { Low } \\
\text { floor }\end{array}$ & 88 & 12 & 1 \\
\hline $\begin{array}{c}\text { SC K230V single decker, } \\
\text { low floor }\end{array}$ & $\begin{array}{c}\text { Scania K230 UB } \\
\text { Euro V }\end{array}$ & Single & $\begin{array}{c}\text { Low } \\
\text { floor }\end{array}$ & 85 & 12 & 1 \\
\hline VL B10 single decker, step & $\begin{array}{c}\text { Volvo B10M } \\
\text { Mark IV }\end{array}$ & Single & Step & 83 & 12 & 1 \\
\hline $\begin{array}{c}\text { MB O405 single decker, } \\
\text { step }\end{array}$ & $\begin{array}{c}\text { Mercedes-Benz } \\
\text { O405 }\end{array}$ & Single & Step & 85 & 12 & 1 \\
\hline $\begin{array}{c}\text { MB OC500 single decker, } \\
\text { low floor }\end{array}$ & $\begin{array}{c}\text { Mercedes-Benz } \\
\text { OC500LE }\end{array}$ & Single & $\begin{array}{c}\text { Low } \\
\text { floor }\end{array}$ & 90 & 12 & 1 \\
\hline $\begin{array}{c}\text { MB O405G articulated- } \\
\text { single decker, step }\end{array}$ & $\begin{array}{c}\text { Mercedes-Benz } \\
\text { O405G }\end{array}$ & $\begin{array}{c}\text { Single- } \\
\text { articulated }\end{array}$ & Step & 132 & 17.8 & 2 \\
\hline
\end{tabular}

Figure 1 shows the design and layout Scania K230UB Euro V buses. Passengers are restricted to board at front doors and suggested to alight at the rear doors. Two smart card readers are employed on both sides of each door.
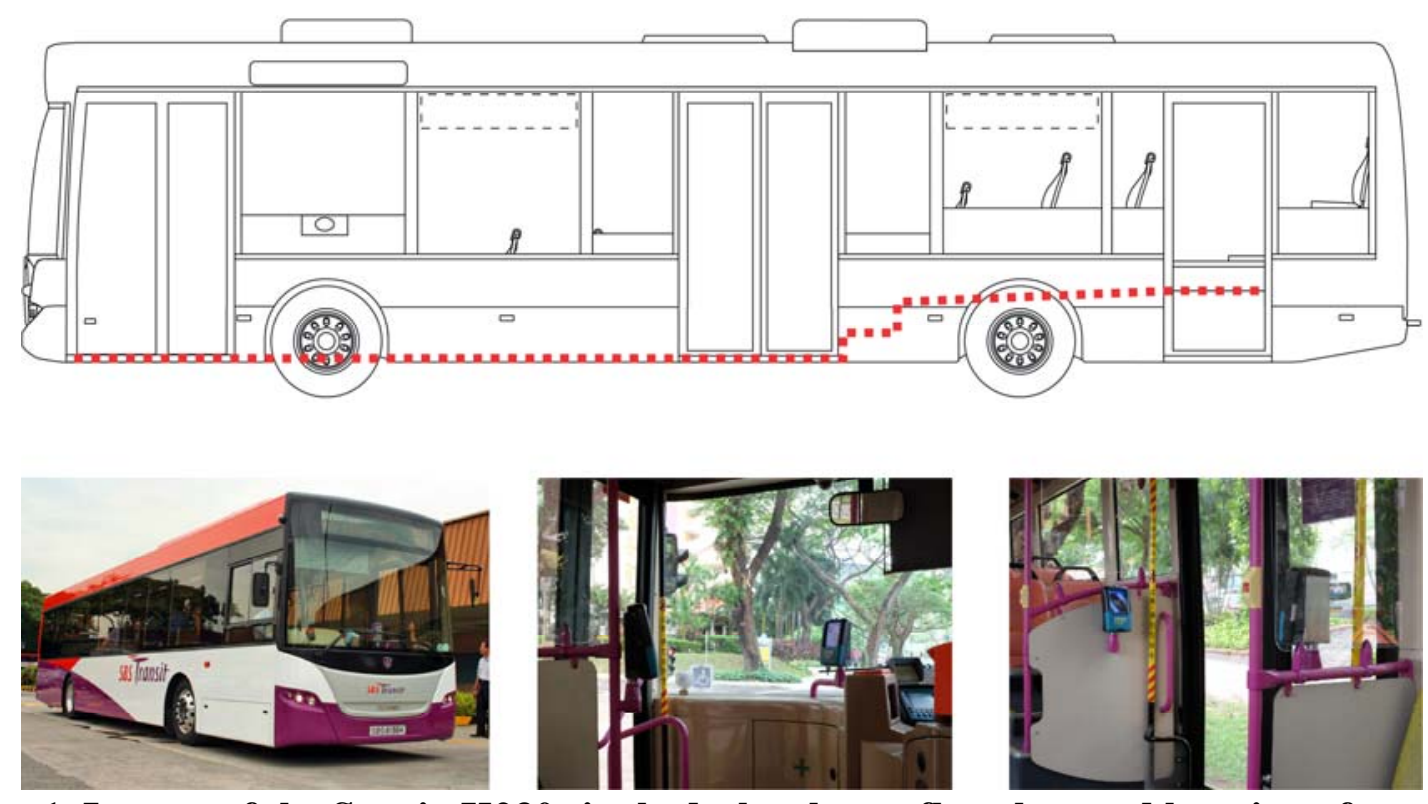

Figure 1, Layout of the Scania K230 single decker lower floor bus and location of smart the card readers (lower middle panel: front door; lower right panel: rear door) 


\section{Descriptive Analysis of Boarding and Alighting Behaviour}

In this section, we compare passenger's boarding and alighting behaviour for different bus types by investigating the interval between successive boarding and alighting activities respectively. We record each service $\times$ stop with the number of boarding/alighting passengers, number of on-board passengers and the corresponding total passenger activity time for boarding and alighting. Thus, the data contains full operation logs along the service route. Note that buses do not stop when there is no boarding or alighting required at a stop.

\subsection{Boarding Interval}

Given two smart readers are deployed at each door, two queues may form when either boarding or alighting in our study. However, we miss information to map each transaction record to the corresponding smart card reader; and thus the interval $h_{B}$ in this study describes the time interval between successive tapping-ins regardless of reader on which each transaction was generated (see Figure 1). In other words, the interval actually measures the inter-tapping-in time between successive transactions at the front door. Figure 2 shows the distribution of boarding intervals for different bus types. Since the front door is able to accommodate two users boarding at the same time, the minimum interval is 0 seconds. Note that some abnormal activities --- e.g., passengers may take their card out after they board the bus --- are also captured in such intervals, imposing increased heterogeneity in our observations. Nevertheless, such abnormal behaviour indeed affects the boarding/alighting processes in practice, so we still take it into account in our analysis and model. 


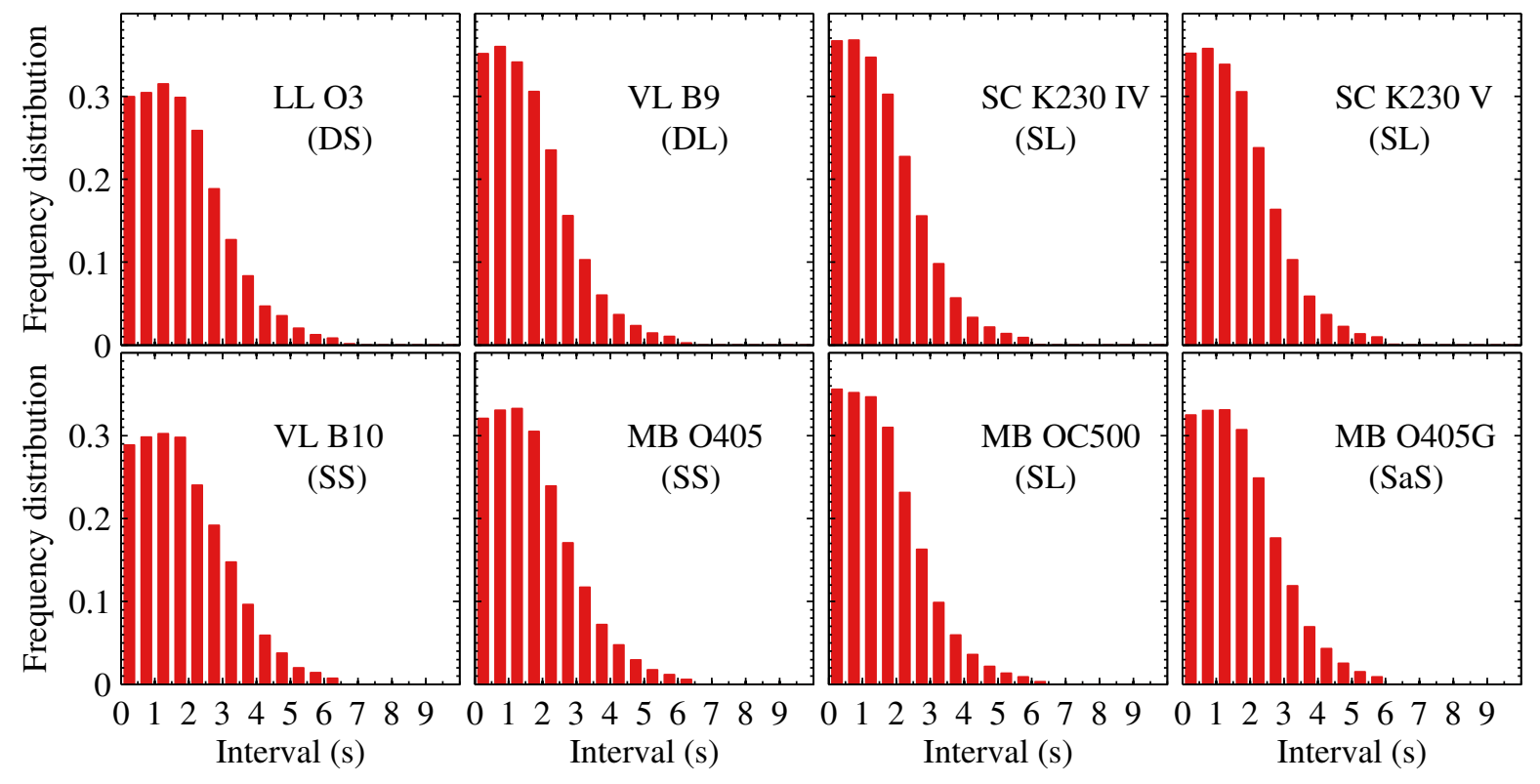

Figure 2, Distributions of boarding interval $P\left(h_{B}\right)$ 


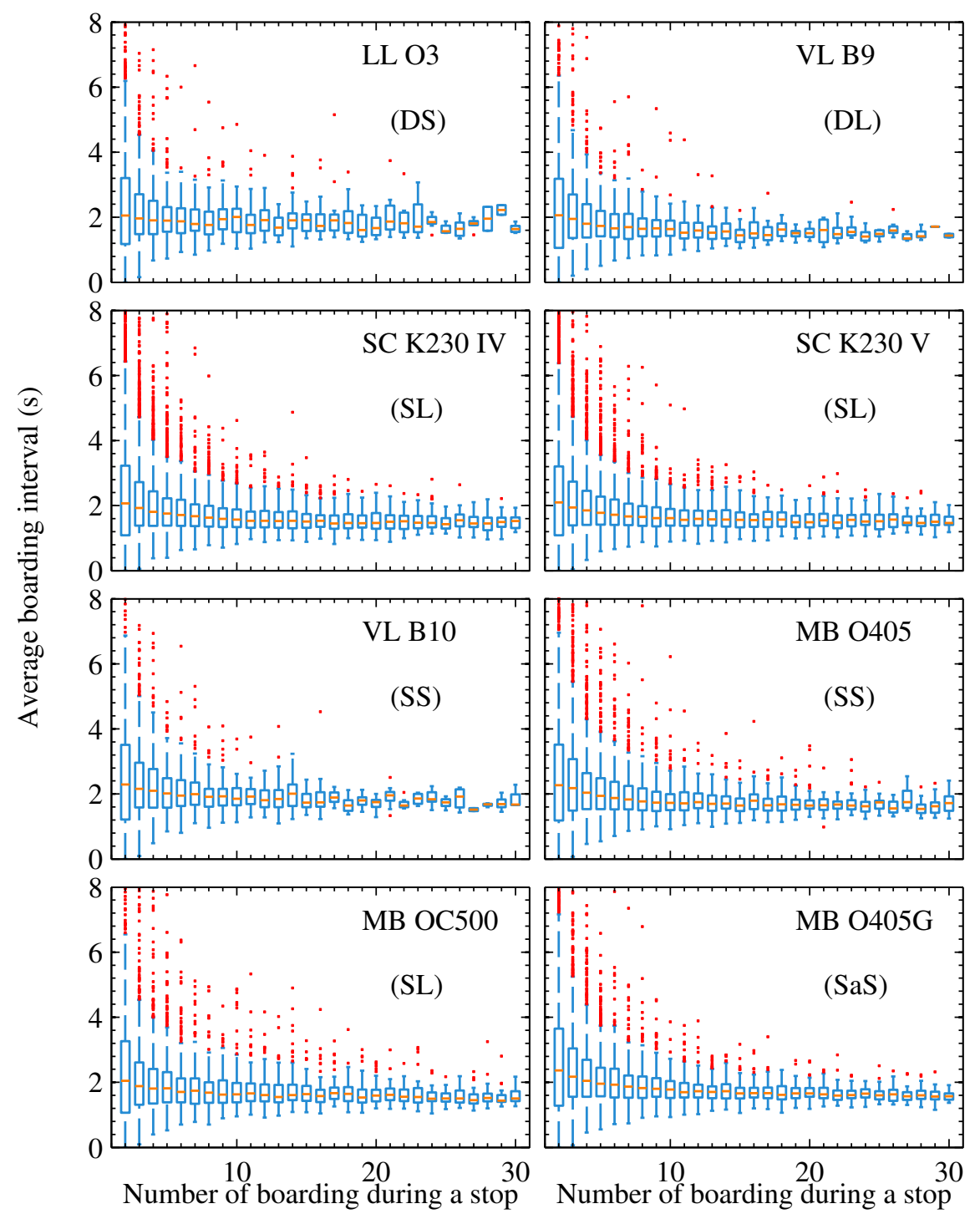

Figure 3 , The trend of average boarding interval $\overline{h_{B}}$ against number of boarding passengers
during a stop

To explore the variation of boarding interval $h_{B}$, we first measure the distributions of $h_{B}$ across the eight bus types. As expected, the distributions for different bus types share similar shapes because all buses have one door only for boarding. Figure 3 shows the trends of average boarding interval $\overline{h_{B}}$ against different number of boarding passengers during a stop. Similar to the saturation flow at signalized junctions, we see that the variability of $h_{B}$ is larger when fewer passengers board, and a more stable interval of around 2 seconds, needs some time to establish itself, indicating the 
lines with fewer, but more heavily used stops should be advantageous from an operational point of view and there exists marginal effect when number of boarding passenger is large.

Table 2, Statistics of boarding interval

\begin{tabular}{|c|r|r|r|}
\hline Bus & Sample size & Mean [s] & Std Dev [s] \\
\hline LL double decker, step & 17,946 & 1.93 & 1.34 \\
\hline VL B9 double decker, low floor & 22,817 & 1.76 & 1.27 \\
\hline SC K230 VI single decker, low floor & 144,752 & 1.72 & 1.25 \\
\hline SC K230V single decker, low floor & 129,198 & 1.76 & 1.26 \\
\hline VL B10 single decker, step & 19,758 & 2.02 & 1.39 \\
\hline MB O405 single decker, step & 64,123 & 1.86 & 1.34 \\
\hline MB OC500 single decker, low floor & 59,386 & 1.68 & 1.22 \\
\hline MB O405G articulated-single decker, step & 115,396 & 1.83 & 1.28 \\
\hline Total & 573,376 & 1.78 & 1.27 \\
\hline
\end{tabular}

The statistics on the boarding interval of different bus types are given in Table 2. For the eight bus types, the average boarding interval per passenger ranges from 1.68 to 2.02 seconds, with standard deviations between 1.22 and 1.39 seconds. Considering each bus type as an observation it stands out that there is a linear correlation between the mean and standard deviation of boarding times:

$$
\operatorname{Std}\left(h_{B}\right)=0.50 \times h_{B}+0.39 \text {, }
$$

with $R^{2}=0.95$ (see Figure 4). This implies that bus configurations with slow boarding times also have a greater variability in boarding, and consequently, in travel times, which has undesirable effects on bus operations and is negatively valued by users.

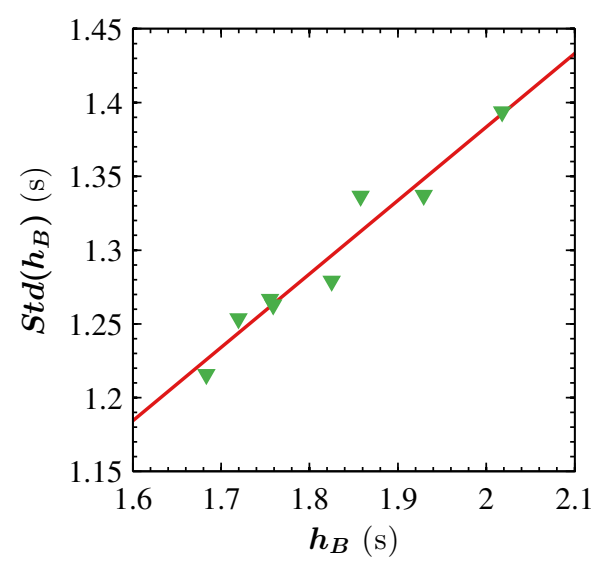

Figure $4, h_{B}$ and $\operatorname{std}\left(h_{B}\right)$ for different bus types 
Other studies found a mean boarding time for on-board smart card validation of $2 s$ / pax, e.g. Bus Rapid Transit Systems in China (Wright and Hook, 2007) and for uncrowded conditions in Santiago de Chile (Fernández et al., 2008). Due to data limitations, previous studies have been unable to trace the relationship between the mean and the standard deviation of boarding time, as done in Figure 4.

To further address the impact of bus characteristics on boarding interval, we used a regression model to measure average cost of each boarding $b$ activity using the following parameters: intercept ( $\beta_{B}$ ), the marginal effect of additional boarding ( $\beta_{B s}$ ), the contribution of floor type $\left(\beta_{D}\right)$, entrance type ( $\beta_{S}$ ), occupancy ( $\beta_{\text {Oc }}$ ) and capacity ( $\beta_{\text {Cap }}$ ) on each boarding activity:

$$
T_{B}=(B-1) \times b+\varepsilon=(B-1) \times\left(\beta_{B}+\beta_{B S} \times(B-1)+\beta_{D} D+\beta_{S} S+\beta_{O C} \text { On } / \text { Cap }\right)+\varepsilon,
$$

where $T_{B}=t_{\text {last }}^{B}-t_{\text {first }}^{B}$ is the total time for boarding for each service $\times$ stop , $B$ represents number of boarding passengers and thus $B-1$ is number of recorded activities, $D$ and $S$ are dummy variables indicating bus types:

$$
D=\left\{\begin{array}{lc}
1 & \text { double decker } \\
0 & \text { single decker }
\end{array}, \quad S=\left\{\begin{array}{cc}
1 & \text { step entrance } \\
0 & \text { low floor entrance }
\end{array},\right.\right.
$$

Cap represents vehicle capacity, On/Cap ( $[0,1]$, number of on-board passengers/capacity) indicates occupancy before boarding and alighting and $\varepsilon$ is the residual or unexplained variance.

Table 3, Regression analysis of total boarding time

\begin{tabular}{ccccccc}
\hline Parameter & Description & Unit & Estimate & SE & t-stats & $p$-value \\
\hline$\beta_{B}$ & Intercept & s/pax & 1.951 & 0.003 & 648.05 & 0.000 \\
$\beta_{B s}$ & Number of recorded activities & s/pax ${ }^{2}$ & -0.017 & 0.000 & -259.13 & 0.000 \\
$\beta_{D}$ & Double decker & s/pax & 0.047 & 0.007 & 7.21 & 0.000 \\
$\beta_{S}$ & Step entrance & s/pax & 0.156 & 0.003 & 57.02 & 0.000 \\
$\beta_{O c}$ & Occupancy & s/pax & 0.340 & 0.008 & 48.78 & 0.000 \\
\hline Adjusted $\mathrm{R}^{2}$ & 0.914 & & Observations & & 61555 &
\end{tabular}

Note that the regression model does not contains intercept as we match $T_{B}$ to the $(B-1)$ recorded activities exactly. SE indicates standard error.

Table 3 shows the regression result of Equ. (5) using total boarding time observed with more than one passengers for all types. The average time without considering specific vehicle attributes is 
about 1.95s/pax. We find that number recorded activates have a negative impact on average boarding time, which is in accord with Figure 3, suggesting that the average boarding interval decreases as the number of boarding passengers increases within our range of observations. Step entrance increases average boarding times significantly by $0.156 \mathrm{~s}$. Double decker buses also show a statistically significant influence on boarding behaviour; however, the effect is small (0.047s) as passengers can continue boarding while passengers that boarded ahead are walking in the aisle or upstairs. Note that occupancy has significant negative impact on boarding flows, as they incur more friction within the vehicles, delaying the boarding processes. On the other hand, vehicle capacity diminishes boarding time significantly, as larger capacity may reduce the in-vehicle frication. Taken together, despite number of boarding passengers, the boarding processes is affected by the entrance type and occupancy: although boarding time is largely covered by the time spent on swiping smart cards and waiting for transaction responses, low floor with large capacity still offers better user experience since passengers do not have to walk up steps, in particular for senior citizens.

\subsection{Alighting Behaviour}

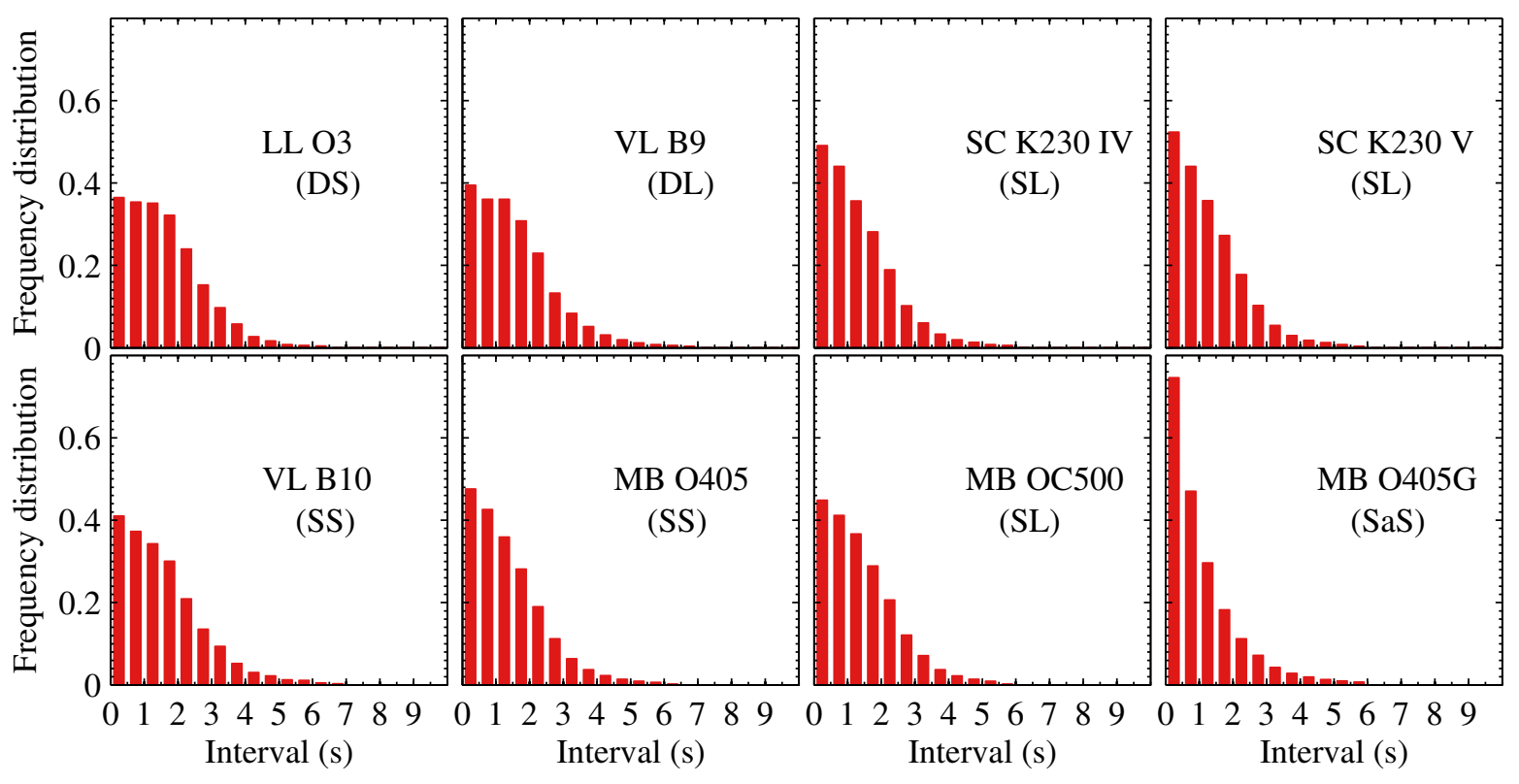

Figure 5, Distributions of alighting interval $P\left(h_{A}\right)$

Analogous to the definition of boarding interval, alighting interval $h_{A}$ is defined as the time interval between two successive tapping-offs. Figure 5 shows the distributions of alighting interval for the different bus types. Unlike the boarding activities, significant heterogeneity is observed in alighting. It should be noted that the distribution of articulated bus (MB O405G) is substantially different from others in Figure 5 as they have two doors for alighting, therefore shorter intervals are 
observed. The detailed statistics are listed in Table 4. Observations in which passengers tap out before the bus arrives at the stop were removed, thus, the sample size of alighting interval is smaller than that of boarding. The average alighting time per passenger varies from $1.26 \mathrm{~s}$ to $1.78 \mathrm{~s}$. Overall the average alighting time is about 0.30 s shorter than the average boarding time $(1.48 \mathrm{~s}$ vs $1.78 \mathrm{~s}$ per passenger).

Table 4, Statistics of alighting interval

\begin{tabular}{|c|r|r|r|}
\hline Bus & Sample size & Mean [s] & Std Dev [s] \\
\hline LL double decker, step & 8810 & 1.78 & 1.30 \\
\hline VL B9 double decker, low floor & 11305 & 1.75 & 1.32 \\
\hline SC K230 VI single decker, low floor & 69388 & 1.54 & 1.25 \\
\hline SC K230V single decker, low floor & 63039 & 1.50 & 1.26 \\
\hline VL B10 single decker, step & 9682 & 1.78 & 1.37 \\
\hline MB O405 single decker, step & 36846 & 1.52 & 1.22 \\
\hline MB OC500 single decker, low floor & 34647 & 1.48 & 1.14 \\
\hline MB O405G articulated-single decker, step & 64736 & 1.26 & 1.23 \\
\hline Total & 298453 & 1.48 & 1.23 \\
\hline
\end{tabular}

${ }^{*}$ Given there are two doors used for alighting in articulated bus, the value here is not the defined alighting interval anymore.

As in the case of boarding, the standard deviation of alighting times is also positively correlated to its mean, as shown in Figure 6 (the regression does not include articulated buses --- Type 8). In this case, a linear relationship is not as clear as that of boarding with $R^{2}=0.73$ :

$$
\operatorname{Std}\left(h_{A}\right)=0.45 \times h_{A}+0.53
$$




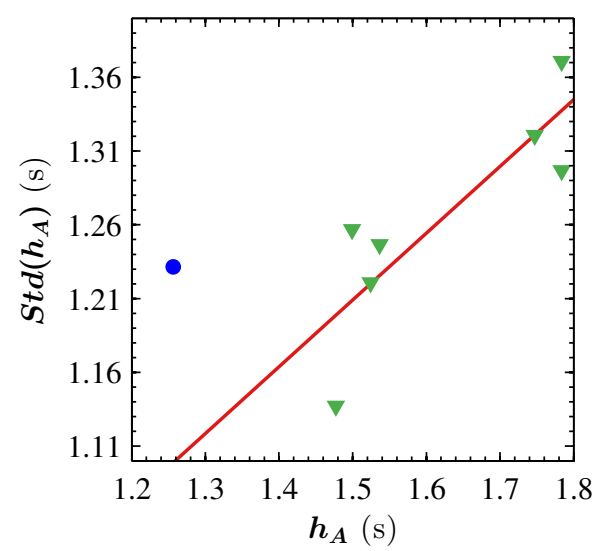

Figure 6, $h_{A}$ and $s t d\left(h_{A}\right)$ for different bus types (blue circle represents MB O405G)

Similarly, to address the impact of bus characteristics on alighting interval, we applied regression model to measure average time of each alighting activity $a$ using: intercept $\left(\alpha_{A}\right)$, the diminishing marginal effect of additional alighting $\left(\alpha_{A s}\right)$, the contribution of floor type $\left(\alpha_{D}\right)$, entrance type ( $\alpha_{S}$ ) and occupancy ( $\alpha_{O c}$ ) on each boarding activity:

$$
T_{A}=(A-1) \times a+\varepsilon=(A-1) \times\left(\alpha_{A}+\alpha_{A s} \times(A-1)+\alpha_{D} D+\alpha_{S} S+\alpha_{O c} \text { On } / \text { Cap }\right)+\varepsilon,
$$

where $T_{A}=t_{\text {last }}^{A}-t_{\text {first }}^{A}$ is the total time for boarding for each service $\times$ stop , $(A-1)$ is the number of recorded alighting activities.

Table 5, Regression analysis of total alighting time

\begin{tabular}{ccccccc}
\hline Parameter & Description & Unit & Estimate & SE & t-stats & $p$-value \\
\hline$\alpha_{A}$ & Intercept & s/pax & 1.691 & 0.006 & 261.74 & 0.000 \\
$\alpha_{A s}$ & Number of recorded activities & s/pax ${ }^{2}$ & -0.014 & 0.000 & -66.04 & 0.000 \\
$\alpha_{D}$ & Double decker & s/pax & 0.217 & 0.009 & 24.40 & 0.000 \\
$\alpha_{S}$ & Step entrance & s/pax & 0.016 & 0.005 & 3.09 & 0.002 \\
$\alpha_{O c}$ & Occupancy & s/pax & -0.082 & 0.019 & -4.41 & 0.000 \\
\hline Adjusted R & 0.879 & Observations & 23083 & \\
\hline
\end{tabular}

* Articulated buses are excluded in estimating model parameters.

Given that the alighting process on an articulated bus is considerably different from other types, we did not take the observations on those buses into account. Table 5 shows the regression result of Equ. (8). The average time across all bus types is about 1.69s/pax. We also find that number recorded activates have a negative impact on average boarding time, diminishing the effect of 
additional alighting for $0.014 \mathrm{~s}$ less, similar to the value of $\beta_{B s}$. The effect of step entrance is significant but small, increasing average alighting time by $0.016 \mathrm{~s}$. The results are in accord with York (1993), which compared buses with one, two and three entrance steps in London, finding that more steps does increase average alighting times. However, double decker buses do show a statistically significant and great influence on alighting behaviour. This suggests that on double decker buses, passengers are more likely to wait upstairs until the bus comes to a full stop before they start walking downstairs on the narrow steps to alight, as usually observed in double decker buses in Singapore. Occupancy also plays a significant role. Different from what we find for boarding process, a high occupancy actually speed up the alighting process. This might be due to passengers feeling crowded or due the pressure from other alighting passengers. Taken together, the alighting process is dominated by the entrance type, occupancy, and in particular double decker. Therefore, it follows that the impact of steps on both boarding and alighting need to be studied in each specific context, taking into account differences due to number and height of steps, and width and location of doors.

In Singapore, it is also observed in the field that, apart from the mentioned effects, both boarding and alighting queues can come to a halt owing to random events, such that when passengers forget to prepare their smart cards before their boarding/alighting. On the other hand, crowding inside vehicles is also likely to lengthen boarding and alighting. In such situations, the dwell time model (II) (Equ. (3)) fails to capture any friction effect amongst passengers. Therefore, a new passenger activity time model is proposed below given the above findings.

\section{Modelling Passenger Activity Time for Restricted Flows}

The friction among boarding, alighting and on-board passengers has shown its importance in determining bus dwell time in the literature (Lin and Wilson, 1992; Dueker et al., 2004; El-Geneidy and Vijayakumar, 2011; Fletcher and El-Geneidy, 2013; Tirachini, 2013). However, the factors resulting in such friction were not studied given the lack of microscopic passenger activity observations. In this section, we try to explore such friction by analysing the cumulative boarding, alighting and on-board curve over time. Then, models for passenger activity time (without considering the time to open and close doors) are estimated and analysed.

Boarding and alighting processes can be treated as pedestrian flows with the smart card reader as their checkpoint. Given the mentioned dynamics, boarding passengers might form a stable flow when the interval is less than a certain level. Thus, using the time-stamped passenger activities, we 
can find how the number of boarding and alighting passengers varies with time during a stop. In Figure 7, we show four types of cumulative boarded, alighted and on-board curve over time identified from SC K230 VI single decker, low floor buses. To separate boarding and alighting flows, the cumulative alighting curve is shown on the negative axis. Time is referenced by setting the first activity time (either boarding or alighting) as zero. Thus, both the cumulative boarding and alighting curves increase with time (note that the alighting curve is also increasing, but it is projected on the negative axis). Given that the number of on-board passengers is available in our data, we can also plot the cumulative on-board passengers. Thus, for example, panel [1] shows a process with 34 onboard passengers before the bus stopped, 46 boarding passengers and 4 alighting passengers. We can see that total activity time is mainly determined by boarding activities whereas alighting activities happened simultaneously. We call such process 'boarding dominates'. Total time of such processes could be estimated using Equ (5), determining boarding time as total activity time ( $A c=T_{B}$ ). Similarly, panel [2] shows an 'alighting dominates' process (on-board 61, boarding 0, and alighting 61) and we may estimate activity time as $A c=T_{A}$ using Equ (8). When number of boarding and alighting processes happen simultaneous, total activity time is determined by the longer process (see panel [3], boarding process is slightly longer than alighting). Such cases exist when the number of on-board passenger is not large and the corresponding total activity time is the longer process ( $\left.A c=\max \left\{T_{B}, T_{A}\right\}\right)$. However, if a bus is almost full before it stops, the boarding flow is delayed and frictions between boarding and alighting flows should be considered. We show such a process with on-board 61, boarding 32 and alighting 45 in panel [4]. Given the large occupancy, the boarding process was delayed for 28 seconds. In this case, alighting happens first, and boarding starts after the number of on-board passengers is less than certain level (about 35 in this case). We call this value as ‘critical occupancy’ $\mathrm{Cr}$ hereafter. 

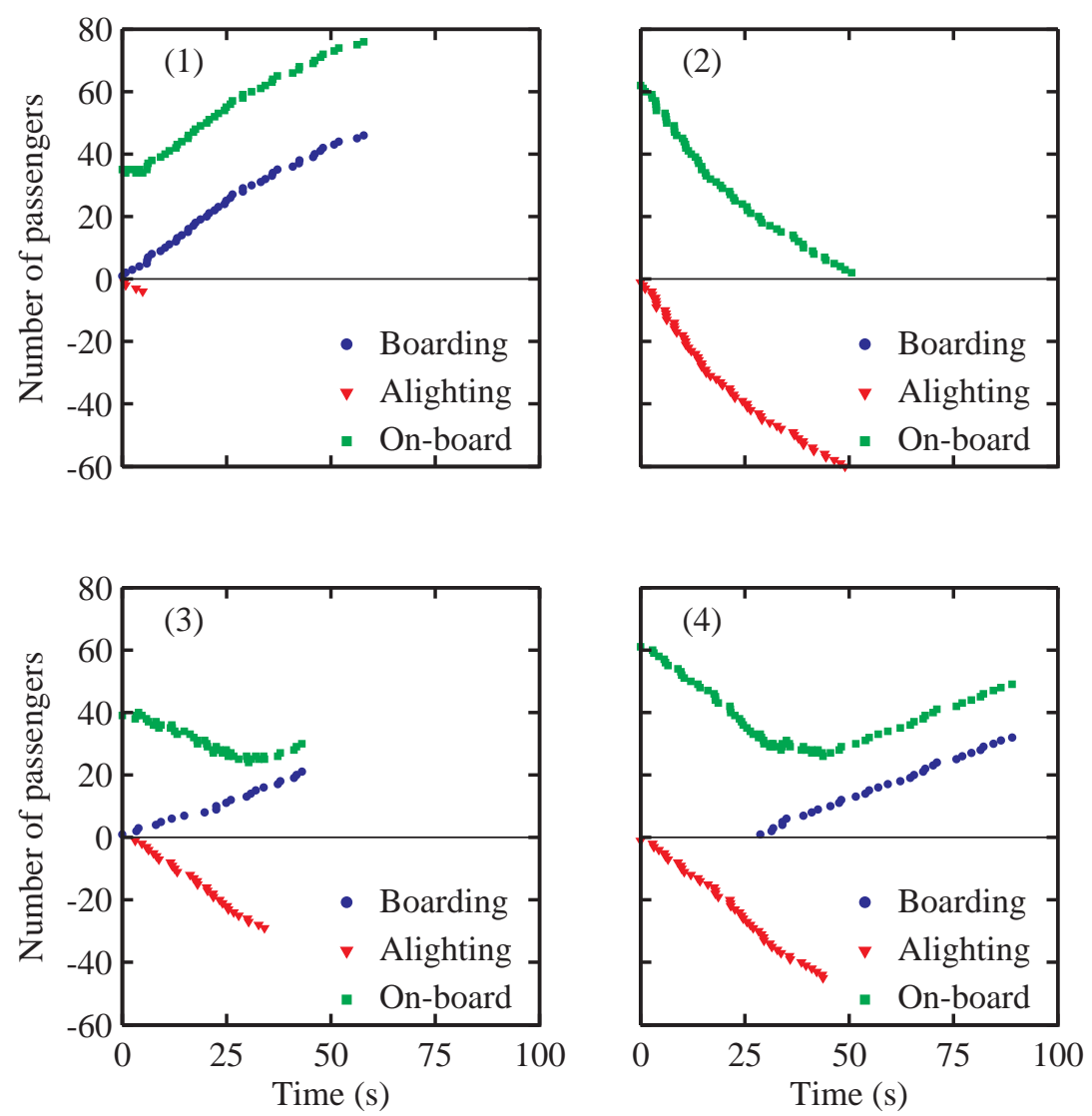

Figure 7, Boarding/alighting flow and instantaneous on-board passengers (SC K230 VI single decker, low floor)

Therefore, we can see that passenger activity time is determined by three variables, i.e. the number of passengers boarding $B$, alighting $A$, and on-board $O n$. Based on the patterns observed in Figure 7, we assume that both boarding time and alighting time is in linear with the number of activity passengers respectively, and propose a new model that considers both boarding/alighting dynamics and the interactions of on-board passengers (note that the recorded total passenger activity time is the interval between first and last- $n$th activities, so only $(n-1)$ intervals are taken into account):

$$
A c= \begin{cases}(B-1) \times b & \text { pattern (1) } \\ (A-1) \times a & \text { pattern (2) } \\ \max \{(B-1) \times b,(A-1)\} & \text { pattern (3) } \\ \max \{(B-1) \times b+(O n-C r) \times a,(A-1) \times a\} & \text { pattern (4) }\end{cases}
$$


where $B$ and $A$ denote the number of boarding and alighting passengers respectively, and $O n$ represents the number of on-board passengers. All together, Equ. (9) can be summarized as the combined model III (see Figure 8):

Model III $A c=\max \{(B-1) \times b+(\max (O n-C r, 0)) \times a,(A-1) \times a\}$.

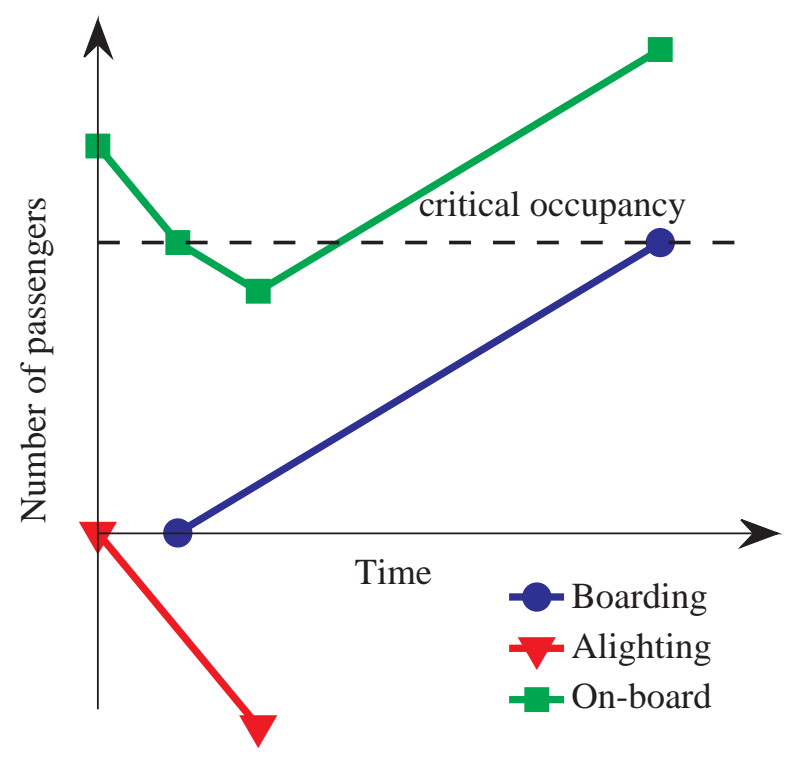

Figure 8, Temporal cumulative curves of boarded, alighted and on-board passengers for restricted flows

\section{Analysis and Results}

Given the operation scheme is simultaneous boarding and alighting, we compare model II with the new model III for the activity time based on the large quantity of observations extracted from the smart card data. To insure the consistency of the two models, we ignore the recovery time to open and close doors and only model passenger activity time ( $A c$ ) determined by the first and last boarding/alighting. Thus, given the formulation of model II, total activity time is determined by the longer process between boarding and alighting:

$$
\text { Model } \mathrm{II}^{3} \quad A c=\max \{(B-1) \times b,(A-1) \times a\}+\varepsilon
$$

where $b=\beta_{B}+\beta_{B S} \times(B-1)+\beta_{D} D+\beta_{S} S+\beta_{O c} O c$ and $a=\alpha_{A}+\alpha_{A s} \times(A-1)+\alpha_{D} D+\alpha_{S} S+\alpha_{O c} O c$. In model III, we assume that critical capacity is in proportion with the total capacity --- $\mathrm{Cr}=\gamma \mathrm{Cap}$.

\footnotetext{
${ }^{3}$ Note that the time for first activity (either boarding or alighting) is not captured in the smart card data,
} 
Thus, model III can be demonstrated in a similar way Equ (11). However, note that boarding happens only when load is lower than critical capacity $\mathrm{Cr}$, so the average boarding time should be revised as:

$$
b=\beta_{B}+\beta_{B s} \times(B-1)+\beta_{D} D+\beta_{S} S+\beta_{O c} \gamma C a p .
$$

and the average alighting time before load reach $\mathrm{Cr}$ is different from should be:

$$
a^{\prime}=\alpha_{A}+\alpha_{A s} \times(\mathrm{On}-\mathrm{Cr})+\alpha_{D} D+\alpha_{S} S+\alpha_{O c} \mathrm{On} / \mathrm{Cap},
$$

Taken together, the regression model III is formulated as:

$$
A c=\max \left\{(B-1) \times b+(\max (\text { On }-\gamma \text { Cap }, 0)) \times a^{\prime},(A-1) \times a\right\} .
$$

Regression models are estimated for Equ. (10) (model III) and (11) (model II). Similar to the estimation of boarding/alighting processes, we only include observations in which either number of passengers boarding or number of alighting per bus stop are greater than or equal to 2 ( $B \geq 2$ or $A \geq 2$ ). Table 6 summarizes the descriptive results of the observed data at each service $\times$ stop used in regression analysis. We used MATLAB Statistical Toolbox to do the regression, which uses Levenberg-Marquardt least squares algorithm to estimate models II and III (Seber and Wild, 2003). Different indicators show the quality of these two models.

Table 6, Descriptive results of observed data

\begin{tabular}{ccccc}
\hline & unit & mean & MIN & MAX \\
\hline Activity time $A c$ & s & 16.95 & 2.03 & 255.06 \\
Number of boarding passengers $B$ & pax & 7.12 & 0 & 79 \\
Number of alighting passengers $A$ & pax & 3.83 & 0 & 74 \\
Number of on-board passnegers $O c$ & pax & 21.68 & 0 & 99 \\
\hline
\end{tabular}

We set the initial value for critical occupancy as 0.5. Initial values for other parameters are set as the previous estimates in the regression on boarding and alighting separately. The regression results are shown in Table 7. Given the absence of in-vehicle friction (see Figure 7, panel (4)), model II gives a high estimate of upper decker on boarding time $(0.33 \mathrm{~s} /$ pax $)$, which is clearly higher than the estimate in Table 3 (0.05s/pax). Moreover, occupancy is estimated to increase alighting time, showing an opposite effect to the separate model on alighting (Table 5) and our intuition. Although we have a lower coefficient of determination in model III, the results are more reasonable than model 
II in terms of factor contribution compared to previous separate models. By introducing critical occupancy as one parameter in model III, we find that the effect of initial occupancy becomes not significant ( $p$-value $=0.616$ ). The critical occupancy is estimated as $63 \%$ of total capacity for all bus types, and its contributions becomes very significant in the regression analysis. The marginal effects of boarding and alighting activities (i.e. the quadratic terms $\beta_{B s}$ and $\alpha_{A s}$ ) are also identified to be significant, both reducing the total activity time in the range of our observations. In additional, when taking all data into consideration, the effect of upper decker on boarding becomes not significant, indicating that upper decker can be a good choice when most on-board passengers alight together. Taken together, the proposed model III performs well in relating the physical characteristics of vehicles to the boarding/alighting and on-board friction dynamics observed from the smart card dataset. 
Table 7, Results of regression analysis on activity time model II and III

\begin{tabular}{|c|c|c|c|c|c|c|c|c|c|c|}
\hline Parameter & Description & Unit & Estimate & SE & t-stats & $p$-value & Estimate & SE & t-stats & $p$-value \\
\hline & & & \multicolumn{4}{|c|}{ model II } & \multicolumn{4}{|c|}{ model III } \\
\hline$\beta_{B}$ & Intercept & s/pax & 2.009 & 0.005 & 403.13 & 0.000 & 2.050 & 0.117 & 17.47 & 0.000 \\
\hline$\beta_{B s}$ & Number of recorded activities & $\mathrm{s} / \mathrm{pax}^{2}$ & -0.016 & 0.000 & -128.39 & 0.000 & -0.010 & 0.000 & -66.40 & 0.000 \\
\hline$\beta_{D}$ & Double decker & s/pax & 0.332 & 0.009 & 3.79 & 0.000 & 0.080 & 0.061 & 1.30 & 0.192 \\
\hline$\beta_{S}$ & Step entrance & s/pax & 0.186 & 0.005 & 36.80 & 0.000 & 0.167 & 0.007 & 24.51 & 0.000 \\
\hline$\beta_{O c}$ & Occupancy & s/pax & 0.359 & 0.012 & 29.30 & 0.000 & -0.001 & 0.002 & -0.50 & 0.616 \\
\hline$\alpha_{A}$ & Intercept & s/pax & 1.889 & 0.013 & 149.41 & 0.000 & 1.969 & 0.015 & 135.76 & 0.000 \\
\hline$\alpha_{A s}$ & Number of recorded activities & s/pax ${ }^{2}$ & -0.023 & 0.000 & -58.41 & 0.000 & -0.012 & 0.000 & -27.08 & 0.000 \\
\hline$\alpha_{D}$ & Double decker & s/pax & 0.235 & 0.017 & 14.09 & 0.000 & 0.285 & 0.019 & 14.86 & 0.000 \\
\hline$\alpha_{S}$ & Step entrance & s/pax & 0.087 & 0.009 & 9.46 & 0.000 & 0.075 & 0.011 & 7.09 & 0.000 \\
\hline$\alpha_{O c}$ & Occupancy & s/pax & 0.329 & 0.035 & 9.30 & 0.000 & -0.371 & 0.039 & -9.46 & 0.000 \\
\hline \multirow[t]{2}{*}{$\gamma$} & Critical occupancy & 1 & - & - & - & - & 0.6332 & 0.0016 & 381.11 & 0.000 \\
\hline & Number of observations & 41618 & $\mathrm{R}^{2}$ & 0.870 & & & $\mathrm{R}^{2}$ & 0.844 & & \\
\hline
\end{tabular}




\section{Summary and Conclusions}

The new electronic smart card systems, as implemented in Singapore, give us a new and much deeper insight into the operational processes of bus boarding and alighting than ever before: more observations, more variance across bus types, and wider range of operating conditions.

Having reconstructed the operations for each combination of service per stop, we were able to describe and then model the three processes of interest here: boarding, alighting and (total) passenger activity time (without the door opening and closing times). We provided explanations for the different performance based on our understanding of the operational characteristics. Boarding is consistently slower than alighting by about 0.3 seconds. It becomes clear that single decker buses with low floor entrance speed up the boarding processes. Although the upper deck also shows a statistically significant effect in slowing down the boarding process, its contribution is trivial comparing to step entrance. However, in terms of alighting, the upper deck does play a significant role in delaying the alighting for more than 0.2 seconds per activity, as the steep stairs discourage passengers to walk down until the bus has come to a complete stop. The existence of step entrance also delays the alighting process a little bit for about $0.01 \sim 0.02$ seconds per activity. The quadratic terms are found to determine both boarding time and alighting time significantly, indicating that average boarding/alighting interval decreases as the number of activities increases, which shows a diminishing marginal effect. In other words, on average the boarding and alighting is faster, when demand is greater in total, as observed in the marginal diminishing effect parameter ( $\beta_{B s}$ and $\beta_{A s}$ ). Interestingly, the occupancy before boarding/alighting starts is found to lengthen the boarding time but shorten the alighting time significantly. Other operational factors such as peak/off-peak and whether are taken into account in this paper; however, they may influence passenger behaviour as well. This would be an interesting future research question.

The joint model of passenger activity times we proposed here shows clearly, that vehicle occupancy determines the regime of the two processes and the overall activity time. Beyond a critical occupancy level of about $60 \%$ of the total bus capacity, the internal friction prevent passengers from boarding, as the alighting passengers have to reduce that critical level of occupancy for the boarding process to properly start. The conventional dwell time models for simultaneous boarding/alighting --which is model II in this paper --- failed to observe and take such effect into account.

Our data are limited to a regime where the front door and rear door are primarily used for boarding and alighting, respectively. In crowded conditions, however, it is common that travellers alight trough both doors while boarding is only allowed through the front door to assert fare 
collection. Therefore, no conclusion can be drawn on the effectiveness of such boarding and alighting scheme and compared to other setups. Although the use of smart card data shows its advantages, we failed to account for other vehicle configuration and human factors, such as whether a particular vehicle is friendly to wheelchairs, bicycles, and strollers without doing a comprehensive field survey. Similarly, we did not account for potential stop configuration effects such as availability of a bus bay and crowdedness on the waiting platform. Passenger attributes --- such as age and gender --- also play a crucial role in determining boarding/alighting dynamics; however, such information is only available from a field survey. Furthermore, the techniques only enable us to observe passenger activity time, hindering us from identifying service interruption, disruptions, scheduled delays, gap time to enter the traffic again, and on-stop traffic controls which may cause abnormal dwell time observations. Thus, a potential direction is to combine survey data and smart card data together in interpreting passenger behaviour patterns. In the studied transport system of Singapore, during the boarding and alighting processes each passenger needs to swipe the ticket over the card reader. This is also a source of variability as some passengers have the smart card prepared for swiping while others needs first to find it in their pockets, imposing heterogeneity on our analysis. This opens up further research questions to address the practical questions on how to improve the situation with the given bus fleet. First, it would be interesting to see whether and when the boarding and alighting process could be sped up and variability reduced, by installing additional card readers at the bus stop so that passengers could tap in and out the system outside the bus. Second, for stops where either preliminary boarding or alighting regimes dominate, it might make sense to allow boarding or alighting through all doors to increase the flow. For practical application, the regularity of such scheme in terms of time of the day and bus stop is crucial as one would need to communicate with passengers in advance when boarding or alighting through both doors is allowed (Jara-Díaz and Tirachini, 2013). To this end, however, a multi-week passenger transaction data set would be needed to account for the various potential sources of demand variability such as special events, public holidays, school holidays and weather conditions.

Our results have a number of potential implications for practice and policy. First, the relationship between passenger activity time duration and bus capacity can be incorporated into models on optimal bus size; such relationship should be taken into account when deciding if having rigid, articulated or up-decker buses. Double-decker does not slow boarding, but it does do so for alighting. These buses might be good choice when demand is high and most passengers alight at a particular bus stop, for example commuting buses collecting workers from different housing location to same 
working location. Step entrance increases boarding time significantly, while it does not deley alighting processes much.

Second, the variability of boarding and alighting times have likely but unknown effects on bus interval variability, and consequently, on increasing waiting times. Together with traffic congestion and demand heterogeneity, dwell time variability increases the risk of service unreliability (Vuchic, 1981; Strathman and Hopper, 1993). The correlation between dwell time variability, service reliability and bus bunching needs further scrutiny, in particular, on determining how they interact to influence optimal bus headway, optimal bus stop spacing and control strategies such as bus holding (Hickman, 2001; Strathman et al., 2002). This is particularly urgent when the existing operations are characterised by high unreliability and a large mix of different bus types. Finally, the results of boarding and alighting dynamics models can directly be applied to calibrate large-scale, agent-based transport simulation such as MATSim (http://www.matsim.org) or Transims (https://code.google.com/p/transims/) which allows us to evaluate how different bus types and deployment schedules impact service quality and reliability.

\section{Acknowledgements}

The research is funded by the National Research Foundation of Singapore, the funding authority of the Future Cities Laboratory. Alejandro Tirachini acknowledges support from Fondecyt, Chile (Grant 11130227) and from the Complex Engineering Systems Institute (Grants ICM P-05-004-F, CONICYT FBO16). We thank Land Transport Authority of Singapore for providing the CEPAS smart card data used in this study. The views and conclusions in this paper are those of the authors and should not be expressed, implied or interpreted as representing Land Transport Authority.

\section{References}

Aashtiani, H.Z., Iravani, H. (2002) Application of dwell time functions in transit assignment model. Transportation Research Record: Journal of the Transportation Research Board 1817, 88-92.

Abkowitz, M.D., Engelstein, I. (1983) Factors affecting running time on transit routes. Transportation Research Part A: General 17, 107-113.

Barry, J.J., Newhouser, R., Rahbee, A., Sayeda, S. (2002) Origin and destination estimation in New York City with automated fare system data. Transportation Research Record: Journal of the Transportation Research Board 1817, 183-187.

Bates, J., Polak, J., Jones, P., Cook, A. (2001) The valuation of reliability for personal travel. Transportation Research Part E: Logistics and Transportation Review 37, 191-229. 
Batley, R., Ibáñez, N. (2009) Randomness in preferences, outcomes and tastes, an application to journey time risk. Proceedings of International Choice Modelling Conference, Yorkshire.

Currie, G., Delbosc, A., Harrison, S., Sarvi, M. (2013) Impact of Crowding on Streetcar Dwell Time. Transportation Research Record: Journal of the Transportation Research Board 2353, 100-106.

Daamen, W., Hoogendoorn, S.P. (2003) Experimental research of pedestrian walking behavior. Transportation Research Record: Journal of the Transportation Research Board 1828, 20-30.

Daamen, W., Lee, Y., Wiggenraad, P. (2008) Boarding and alighting experiments: Overview of setup and performance and some preliminary results. Transportation Research Record: Journal of the Transportation Research Board 2042, 71-81.

Dorbritz, R., Lüthi, M., Weidmann, U., Nash, A. (2009) Effects of Onboard Ticket Sales on Public Transport Reliability. Transportation Research Record: Journal of the Transportation Research Board 2110, 112-119.

Dueker, K.J., Kimpel, T.J., Strathman, J.G., Callas, S. (2004) Determinants of bus dwell time. Journal of Public Transportation 7, 21-40.

El-Geneidy, A., Vijayakumar, N. (2011) The effects of articulated buses on dwell and running times. Journal of Public Transportation 14, 63-86.

Fernández, R., De Los Angeles Del Campo, M., Swett, C. (2008) Data collection and calibration of passenger service time models for the Transantiago system. Proceedings of European Transport Conference, The Netherlands.

Fernández, R., Zegers, P., Weber, G., Tyler, N. (2010) Influence of Platform Height, Door Width, and Fare Collection on Bus Dwell Time. Transportation Research Record: Journal of the Transportation Research Board 2143, 59-66.

Fletcher, G., and El-Geneidy, A. (2013) The effects of fare payment types and crowding on dwell time: A fine-grained analysis. Transportation Research Record: Journal of the Transportation Research Board 2351, 124-132.

Furth, P.G. (2000) Data analysis for bus planning and monitoring, TCRP Synthesis 34. Transportation Research Board, National Research Council, Washington DC.

Guenthner, R.P., Hamat, K. (1988) Transit dwell time under complex fare structure. Journal of Transportation Engineering 114, 367-279.

Guenthner, R.P., Sinha, K.C. (1983) Modeling bus delays due to passenger boardings and alightings. Transportation Research Record: Journal of the Transportation Research Board 915, 7-13.

Helbing, D., Buzna, L., Johansson, A., Werner, T. (2005) Self-organized pedestrian crowd dynamics: experiments, simulations, and design solutions. Transportation Science 39, 1-24.

Hickman, M. D. (2001). An analytic stochastic model for the transit vehicle holding problem. Transportation Science 35(3), 215-237.

Hollander, Y. (2006) Direct versus indirect models for the effects of unreliability. Transportation Research Part A: Policy and Practice 40, 699-711. 
Jara-Díaz, S. R., Tirachini, A. (2013). Urban bus transport: open all doors for boarding. Journal of Transport Economics and Policy 47(1), 91-106.

Jara-Díaz, S.R., Gschwender, A., Ortega, M. (2012) Is public transport based on transfers optimal? A theoretical investigation. Transportation Research Part B: Methodological 46, 808-816.

Kraft, W.H., Bergen, T.F. (1974) Evaluation of passenger service times for street transit systems. Transportation Research Record: Journal of the Transportation Research Board 505, 13-20.

Larrain, H., Muñoz, J.C. (2008) Public transit corridor assignment assuming congestion due to passenger boarding and alighting. Networks and Spatial Economics 8, 241-256.

Lee, D.H., Sun, L., Erath, A. (2012) Study of Bus Service Reliability in Singapore Using Fare Card Data. Proceedings of 12th Asia Pacific ITS Forum \& Exhibition, Kuala Lumpur.

Lehnhoff, N., Janssen, S. (2003) Untersuchung und Optimierung der Fahrgastwechselzeit. Der Nahverkehr 21, 14-20.

Levine, J.C., Torng, G.W. (1994) Dwell-Time Effects of Low-Floor Bus Design. Journal of Transportation Engineering 120, 914-929.

Levinson, H.S. (1983) Analyzing transit travel time performance. Transportation Research Record: Journal of the Transportation Research Board 915, 1-6.

Li, M.T., Zhao, F., Chow, L.F., Zhang, H., Li, S.C. (2006) Simulation model for estimating bus dwell time by simultaneously considering numbers of disembarking and boarding passengers. Transportation Research Record: Journal of the Transportation Research Board 1971, 59-65.

Lin, T., Wilson, N.H.M. (1992) Dwell time relationships for light rail systems. Transportation Research Record: Journal of the Transportation Research Board 1361, 287-295.

Meignan, D., Simonin, O., Koukam, A. (2007) Simulation and evaluation of urban bus-networks using a multiagent approach. Simulation Modelling Practice and Theory 15, 659-671.

Milkovits, M.N. (2008) Modeling the factors affecting bus stop dwell time: use of automatic passenger counting, automatic fare counting, and automatic vehicle location data. Transportation Research Record: Journal of the Transportation Research Board 2072, 125-130.

Moreno González, E.G., Romana, M.G., Álvaro, O.M. (2012) Bus dwell-time model of main urban route stops: case study in Madrid, Spain. Transportation Research Record: Journal of the Transportation Research Board 2274, 126-134.

Munizaga, M.A., Palma, C. (2012) Estimation of a disaggregate multimodal public transport OriginDestination matrix from passive smartcard data from Santiago, Chile. Transportation Research Part C: Emerging Technologies 24, 9-18.

Newell, G.F., Potts, R.B., Board, A.R.R. (1964) Maintaining a bus schedule. Proceedings of 2nd Australian Road Research Board (ARRB) Conference, Melbourne.

Padmanaban, R., Vanajakshi, L., Subramanian, S. (2009) Estimation of bus travel time incorporating dwell time for APTS applications. Proceedings of IEEE Intelligent Vehicles Symposium, Xi'an, pp. 955-959. 
Pelletier, M.P., Trépanier, M., Morency, C. (2011) Smart card data use in public transit: A literature review. Transportation Research Part C: Emerging Technologies 19, 557-568.

Prakasam, S. (2008) The evolution of e-payments in public transport: Singapore's experience. Japan Railway \& Transport Review 50, 36-39.

Rajbhandari, R., Chien, S.I., Daniel, J.R. (2003) Estimation of bus dwell times with automatic passenger counter information. Transportation Research Record: Journal of the Transportation Research Board 1841, 120-127.

Rudloff, C., Bauer, D., Matyus, T., Seer, S. (2011) Mind the gap: Boarding and alighting processes using the social force paradigm calibrated on experimental data. Proceedings of 14th International IEEE Conference on Intelligent Transportation Systems, Washington DC, pp. 353-358.

Seber, G.A.F., Wild, C.J. (2003) Nonlinear regression. Wiley, Newark, New Jersey.

Strathman, J.G., Hopper, J.R. (1993) Empirical analysis of bus transit on-time performance. Transportation Research Part A: Policy and Practice 27, 93-100.

Strathman, J. G., Kimpel, T. J., Dueker, K. J., Gerhart, R. L., Callas, S. (2002). Evaluation of transit operations: data applications of Tri-Met's automated Bus Dispatching System. Transportation 29(3), 321-345.

Tirachini, A. (2011) Estimation of travel time and the benefits of upgrading the fare payment technology in urban bus services. Transportation Research Part C: Emerging Technologies 30, 239256.

Tirachini, A. (2013) Bus dwell time: the effect of different fare collection systems, bus floor level and age of passengers. Transportmetrica A: Transport Science 9, 28-49.

Tirachini, A., Hensher, D.A., Rose, J.M. (2013) Crowding in public transport systems: Effects on users, operation and implications for the estimation of demand. Transportation Research Part A: Policy and Practice 53, 36-52.

TRB (2000) Highway capacity manual. Transportation Research Board, National Research Council, Washington DC.

van Oort, N. (2011) Service reliability and urban public transport design. TRAIL Research School, Delft University of Technology.

Vuchic, V.R. (1981) Urban public transportation: systems and technology. Prentice-Hall.

Weidmann, U. (1992) Transporttechnik der Fussgänger. IVT, Institut für Verkehrsplanung, Transporttechnik, Strassen- und Eisenbahnbau, ETH Zürich, Zürich.

Weidmann, U. (1994) Der Fahrgastwechsel im öffentlichen Personenverkehr. IVT, Institut für Verkehrsplanung, Transporttechnik, Strassen- und Eisenbahnbau, ETH Zürich.

Wright, L., Hook, W.B. (2007) Bus rapid transit planning guide, 3rd ed. Institute for Transportation \& Development Policy, New York. 
York, I.O. (1993) Factors affecting bus-stop times, Project report 2. Transport Research Laboratory, Crowthorne. 